\title{
Recruiting Underrepresented Minority Students into Psychiatry Residency: a Virtual Diversity Initiative
}

\author{
Enioluwafe Ojo $^{1}$ (1) $\cdot$ Danielle Hairston $^{2}$
}

Received: 10 August 2020 / Accepted: 29 March 2021 / Published online: 12 May 2021

(C) Academic Psychiatry 2021

\begin{abstract}
Objective The COVID-19 pandemic has significantly hindered medical student career planning and clinical rotations. Recruitment and networking may be more influential in match outcomes than previous cycles. Medical residency training programs have significant challenges in recruiting diverse applicants. The American Psychiatric Association's Black Caucus developed a virtual recruitment event for residency programs with robust diversity initiatives and underrepresented medical students. This article evaluates our methods, short-term results, and influence on participating medical students.

Methods The authors sent web-based invitations to all programs subscribed to the American Association of Directors of Psychiatric Residency Training listserv. Programs that demonstrated intention and commitment to diversity, equity, and inclusion were selected. The authors used various social media platforms and the Black Caucus listserv to advertise to medical students. Student participants received an online feedback survey consisting of multiple-choice and open-ended questions.

Results Thirty-six programs and one hundred seven medical students participated in the 2-day diversity fair. Seventy-six students completed the following survey, which is a response rate of $71 \%$. A majority of students reported that this event strongly influenced their interest in a program (71.05) and are actively considering a residency program they had not previously considered (69.74). A majority of medical students (89.47) strongly agreed that program representatives treated them with professionalism and respect.

Conclusion This event improved communication between highly valued underrepresented minority students applicants and residency programs. A notable majority of participants found the program overwhelmingly beneficial.
\end{abstract}

Keywords Ethnicity $\cdot$ Recruitment $\cdot$ Psychiatry $\cdot$ Diversity $\cdot$ URM

A disparity persists in the quality of and access to mental health care in US ethnic and racial minority patient populations. In its current form, the US psychiatric workforce cannot provide equitable and quality care to diverse communities. The representation discrepancy of underrepresented minorities (URM) is not unique to this specialty but is reflective of trends in all of medicine $[1,2]$. A solution is to recruit and retain more diverse medical students, trainees, and faculty into psychiatry. The transition between medical school and residency is a crucial point in the pipeline for recruitment [3].

Enioluwafe Ojo

enioluwafe_ojo@med.unc.edu

1 University of North Carolina School of Medicine, Chapel Hill, NC, USA

2 Howard University College of Medicine, Washington, DC, USA
The COVID-19 pandemic has disrupted the residency application process in unprecedented ways. The residency application experience for applicants and programs will not be like any other. Medical institutions suspended clinical rotations in their initial response to COVID-19. Subsequently, current clinical rotations have been shortened to accommodate loss of time. Institutions have suspended their audition rotations. This combination has limited student's ability to demonstrate clinical skills and request potential letters of recommendation [4]. Per the Coalition for Physician Accountability's WorkGroup on Medical Students in their Class of 2021 recommendations, all interviews should be conducted virtually, limiting individual opportunities to network. The AAMC workgroup recommends programs commit to online interviews for all applicants. The additional barriers are particularly concerning for URM in medical school [5]. The limitations of this interview season call for novel methods to reach and recruit URM applicants. 
The American Psychiatric Association (APA) Caucus of Black Psychiatrists' leadership is committed to providing medical students of color with exposure to residency programs that recognize a need for improved diversity in psychiatry and its workforce. The caucus leadership sought an avenue to address the perpetual disparity in psychiatry resident recruitment nationally. In 2018, the APA compiled data from several sources, including the Association of American Medical Colleges and Graduate Medical Education for its Resident/Fellow Census. This census report, examining ethnicity among psychiatry residents from 2012 to 2017 , found that nearly three-fourths of PGY1 residents were white and Asian. The third largest category was non-US citizens and non-permanent residents. Consistently, less than $1 \%$ of residents self-identify as American Indian/Alaskan Native or Native Hawaiian/Pacific Islander. Black/African American and Hispanic/ Latino/Spanish Origin categories have experienced slight growth since 2012. Although there was slight growth, the percentage of Black and Latinx psychiatry residents remains in the single digits. [6].

This article outlines our methods and short-term results to support URM medical students in the residency applicant pool during this season. These efforts culminated in a comprehensive, multifaceted diversity initiative.

\section{Method}

Thirty-six programs participated in a 2-day diversity fair. Programs from 20 different states participated: New York, Wisconsin, Georgia, Massachusetts, Pennsylvania, Texas, Kentucky, North Carolina, Maryland, Washington DC, California, Ohio, North Carolina, Connecticut, Louisiana, Vermont, Tennessee, New Jersey, Indiana, and Iowa. Nineteen programs were associated with public institutions, eleven programs were associated with private institutions, and five programs were community programs. The authors recruited participants by e-mail to complete registration through the American Association of Directors of Psychiatric Residency listserv. Registration was open from April 1st to April 30th, 2020. The selection criteria for interested programs included demonstrating intention and commitment to diversity, equity, and inclusion. The registration form explicitly inquired about current and proposed diversity initiatives. If a registered program had not answered the initiative question, organizers would review the program website to ensure criteria were met.

One hundred seven medical students expressed interest in and registered for one or both parts of the event. The medical students were recruited through the Caucus listserv and various social media platforms: Facebook groups, Twitter, and Instagram. The advertisement aimed at online groups that targeted underrepresented minorities in medicine or psychiatry. The Student National Medical Association (SNMA) and the American Psychiatric Association's Black Caucus promoted the event.

Students were encouraged to share information with their programs and communities.

The platform for the conference was Zoom, a video interface that allows for more intimate, personal interactions [7]. Thirty-six programs that completed registration and met the criteria were selected and then assigned to Part 1 or Part 2. Each Part was divided into two sections (I and II), resulting in nine residency programs per section. Each section allotted 80 $90 \mathrm{~min}$, allowing each program to meet four student groups for $20 \mathrm{~min}$. After completion of student registration, medical students completed an interest survey denoting their top five programs of interest. The organizers grouped students based on similar interests and pattern trends. Each student group had between five and nine students, including a student moderator. Student groups were assigned letter labels corresponding to their Zoom breakout room. Programs were matched with student groups who ordered them highly.

Participants were e-mailed personalized schedules the week of the event. Programs and students received Zoom video conference room links, meeting IDs, and passwords the day before the events.

Both Parts began with a preparatory session for students and programs, giving an outline of the event, troubleshooting guidelines, and general introductions.

An event organizer (DH) served as the Zoom host. The host regulated the event, including participant and program entry, breakout room creation and allocation, and troubleshooting. Each Part ended with Medical Student Opportunities in Psychiatry, hosted by the American Psychiatric Association and the American Academy of Child and Adolescent Psychiatry (AACAP).

Anonymous, voluntary online feedback surveys were distributed via e-mail and Zoom chat room after completion of each Part. The surveys were a combination of multiple-choice and open-ended questions. The analysis of survey data was performed under the University of North Carolina at Chapel Hill's Office of Human Research Ethics' approval, study number 20-3382.

\section{Results}

One hundred seven medical students and thirty-six residency programs participated in this two-part event. Seventy-six students completed this survey. Survey questions and student responses were recorded in Tables 1 and 2. The event influenced the student participant's perception of the residencies, with $71.1 \%$ of students strongly agreeing this event positively affected their interest in a program(s) they were previously interested in. A majority of the students $(69.7 \%)$ reported the 
Table 1 Student survey responses by percentage

\begin{tabular}{|c|c|c|c|c|c|}
\hline Question $(N)$ & Strongly disagree & Disagree & Neither disagree nor agree & Agree & Strongly agree \\
\hline $\begin{array}{l}\text { Program representatives treated me with } \\
\text { professionalism and respect }\end{array}$ & $2.64(2)$ & $0.00(0)$ & $2.64(2)$ & $5.26(4)$ & $89.47(69)$ \\
\hline This was an appropriate setting for a residency fair & $2.64(2)$ & $1.32(1)$ & $1.32(1)$ & $25.00(19)$ & $69.74(53)$ \\
\hline $\begin{array}{l}\text { This event positively affected my interest in a } \\
\text { program(s) I was previously interested in }\end{array}$ & $2.64(2)$ & $0.00(0)$ & $6.58(5)$ & $19.74(15)$ & $71.05(54)$ \\
\hline $\begin{array}{l}\text { This event positively affected my interest in a } \\
\text { program(s) I had not considered }\end{array}$ & $2.64(2)$ & $0.00(0)$ & $7.89(6)$ & $23.68(18)$ & $65.79(50)$ \\
\hline $\begin{array}{l}\text { The representatives discussed diversity initiatives in } \\
\text { their programs }\end{array}$ & $2.64(2)$ & $2.64(2)$ & $13.16(10)$ & $25.00(19)$ & $56.58(43)$ \\
\hline Overall, I was satisfied & $2.64(2)$ & $1.32(1)$ & $0.00(0)$ & $19.74(15)$ & $76.31(58)$ \\
\hline
\end{tabular}

event had positively affected their interest in programs they had not previously considered.

Medical students were able to represent themselves in the virtual setting professionally. Among the medical students, $89.5 \%$ strongly agreed the program representatives treated them with professionalism and respect, while $69.7 \%$ strongly agreed the virtual setting was an appropriate setting for the diversity fair.

Every program was intentionally selected for their diversity initiatives. Among the students, 56.6\% strongly agreed that the programs discussed diversity initiatives, $25.0 \%$ agreed they did, $13.2 \%$ disagreed, and $5.3 \%$ strongly disagreed with it.

One hundred percent of students who participated in the event and completed the follow-up reported they would attend another virtual diversity event. A majority (76.3\%) of the students strongly agreed they were satisfied overall with the event.

\section{Discussion}

Currently, the COVID-19 pandemic has created many challenges in medical education. Medical schools, residency programs, and accrediting bodies must adapt drastically to accommodate the changes and maintain equity [5]. URM students, who are already under-recruited, maybe in a particularly vulnerable position. The need for intentional recruitment and network development opportunities for minority medical students is evident.
According to current research, there is a disparity in URM psychiatry residents in the USA [2]. Current literature regarding methods to ensure ethnic diversity among psychiatry applicants is limited. The existence of the disparity necessitates novel methodologies to reach URM applicants, particularly in the travel-restricted and economically burdensome times that the COVID-19 pandemic has created.

This event was the first and only multiple-program psychiatry fair, specifically recruiting underrepresented minorities to the authors' knowledge.

A residency fair in this setting is accessible to students across the nation. The medical student respondents believed the videoconference residency was fair, informative, and applicable for virtual residency interviews. Time and financial resources significantly influence residency placement [8]. The virtual setting program allowed students to participate in networking at no cost, providing equitable recruitment opportunities and eliminating cost-associated discrepancies. Existing literature emphasizes exposing URM students to pertinent faculty, those underrepresented themselves, or those with clinical and research interests of potential relevance to those underrepresented in medicine [9].

Network development was a benefit from this program. The majority of the medical students stated they are now considering applying to a program they had not previously considered. This result is significant for programs that share an interest in recruiting URM trainees. Additionally, students reported that participating residents and program directors shared personal contact e-mails and phone numbers. Students also created social media groups to exchange

Table 2 Student response by percentage to survey question regarding perspective of virtual interviews

\begin{tabular}{|c|c|c|c|c|}
\hline Question & No & $\begin{array}{l}\text { Yes } \\
\text { Positively }\end{array}$ & $\begin{array}{l}\text { Yes } \\
\text { Negatively }\end{array}$ & $\begin{array}{l}\text { Yes } \\
\text { Undefined }\end{array}$ \\
\hline $\begin{array}{l}\text { Did this virtual residency fair influence your perspective about } \\
\text { completing interviews in a virtual setting? }(N)\end{array}$ & $11.7(9)$ & $77.9(60)$ & $7.8(6)$ & $2.6(2)$ \\
\hline
\end{tabular}


program notes and information with each other after the event. The fair allowed URM students to network with their specific interest programs and each other.

Participating programs were able to recruit URM students intentionally. Virtual fairs focusing on select targets, such as this, provide affordable opportunities for intentional recruitment. The programs were screened appropriately, assuring students that involved programs had a sincere interest in diversity initiatives. Systemic racism in medicine has become glaring following recent social injustice incidents, police brutality, and highlighted health disparities during the COVID-19 pandemic. The deaths of George Floyd, Breonna Taylor, Aubrey Ahmad, and subsequent protests have prompted medical students, especially URMs, to become more vocal about seeking programs that commit to addressing racial injustice and promoting diversity. A program's overt interest and commitment to diversity may influence URM students' final rank list [9].

Of note, about $80 \%$ of participants generally agreed that diversity initiatives were discussed. The authors endeavored to facilitate a wide-reaching event using the minority forums immediately at their avail. However, the platform provided was unmoderated beyond the stated explicit purpose and initial screening. To that end, little to no regulation of specific presentations by programs was completed. Program initiators should emphasize the clear outlining of diversity initiatives for participating programs in future events to improve URM applicants' outcomes.

This two-part residency fair was completed in May 2020, 5 months in advance of the ERAS application deadline and 10 months before the individual student rank list was due. It would not be appropriate for students to comment on the potential rank order of programs. However, future studies could study how residency fairs such as this change outcome/behavior. Even so, nearly 90 participants expressed new interest in a previously unconsidered program, which reflects a potential solid behavioral change/outcome.

Current evidence supports URM medical students are underrepresented in the match due to structural barriers. These barriers, such as AOA membership and USMLE exam performances, have exhibited detrimental racial bias for decades $[10,11]$. The impact of virtual interviews on match outcomes has not been studied yet. However, in the absence of audition rotations, this program provides "face-to-face" interaction which may offset the previously mentioned barriers $[10,11]$.

The authors did not require participants to self-report their racial or ethnic identities. Self-selection was assumed through the recruitment methods, which were centered in minority medicine groups. The program recruitment was limited and may not be a representative sample of US psychiatry residency programs. Supporting staff was unable to support a larger number of students and programs. Equally, incorporating each student's preferred programs into their final schedule was difficult. A small number of students and limited time likely accounted for inflexibility in scheduling.

In conclusion, this event improved communication between highly valued underrepresented minority student applicants and residency programs. A substantial majority of participants found the program overwhelmingly beneficial. With the COVID-19 pandemic and heightened national awareness of systematic racism, ethnic variation in psychiatry residents is essential. It will improve the quality of mental health care while advancing health equity. Events like this foster equity and connect URM students with programs that are intentionally seeking diverse applicants. The event should continue and then be expanded. Funding increases and organizing staff expansion are needed to optimize outcomes. There has never been a better time to study the impact of virtual interviews on match outcomes.

Acknowledgements The Student National Medical Association and the American Psychiatric Association affiliated Student Network Group both hosted virtual residency fairs. The authors acknowledge the American Psychiatric Association and the Howard University College of Medicine.

\section{Declarations}

Conflict of Interest On behalf of all authors, the corresponding author states that there is no conflict of interest.

\section{References}

1. Rao S, How PC, Ton H. Education, training, and recruitment of a diverse workforce in psychiatry. Psychiatr Ann. 2018;48(3):143-8.

2. Wyse R, Hwang WT, Ahmed AA, Richards E, Deville C Jr. Diversity by race, ethnicity, and sex within the US psychiatry physician workforce. Acad Psychiatry. 2020;44:523-30. https://doi. org/10.1007/s40596-020-01276-Z.

3. Verduin ML. Improving the recruitment of medical students into psychiatry. Acad Psychiatry. 2017;41(2):207-12.

4. Hammoud MM, Standiford T, Carmody JB. Potential implications of COVID-19 for the 2020-2021 residency application cycle. JAMA. 2020;324(1):29-30. https://doi.org/10.1001/jama.2020. 8911

5. AAMC. Conducting interviews during the coronavirus pandemic [Internet]. 2020 Retrieved $2020 \mathrm{Jul} 6$. Available from: https://www. aamc.org/what-we-do/mission-areas/medical-education/ conducting-interviews-during-coronavirus-pandemic.

6. American Psychiatric Association. 2018 resident/fellow census. 2019 Jan 6. Retrieved July 1st. Available from: https://www. psychiatry.org/File\%20Library/Residents-MedicalStudents/ Residents/APA-Resident-Census-2019.pdf.

7. Barbu CM. Zoom: a spatial data visualization tool (Version 2.0.4). [Internet]. 2013 Retrieved 2020 Jul 5. Available from: https://cran. r-project.org/web/packages/zoom/citation.html.

8. Chang PS, Rezkalla J, Beard M. An analysis of the financial burden associated with the residency match at the University of South Dakota Sanford School of Medicine. S D Med. 2018;71(2):66-9. 
9. Pierre JM, Mahr F, Carter A, Madaan V. Underrepresented in medicine recruitment: rationale, challenges, and strategies for increasing diversity in psychiatry residency programs. Acad Psychiatry. 2017;41(2):226-32.

10. Wijesekera TP, Kim M, Moore EZ, Sorenson O, Ross DA. All other things being equal: exploring racial and gender disparities in medical school honor society induction. Acad Med. 2019;94(4): 562-9. https://doi.org/10.1097/ACM.0000000000002463.
11. Spector ND, Overholser B. Examining gender disparity in medicine and setting a course forward. JAMA Netw Open. 2019;2(6): e196484. https://doi.org/10.1001/jamanetworkopen.2019.6484.

Publisher's Note Springer Nature remains neutral with regard to jurisdictional claims in published maps and institutional affiliations. 